\title{
Erratum to: $\mathcal{H}_{\infty}$ control of linear multidimensional discrete systems
}

\author{
Zhi-Yong Feng · Qinghe Wu • Li Xu
}

Published online: 16 September 2011

(C) Springer Science+Business Media, LLC 2011

\section{Erratum to: Multidim Syst Sign Process DOI 10.1007/s11045-011-0148-1}

An error was found in the original publication. The inequality (57) of Theorem 4 should be

$$
\left[\begin{array}{cc}
R_{i} & I \\
I & S_{i}
\end{array}\right] \geq 0, \quad i=1, \ldots, n
$$

This error is a typo. In our calculations of the application examples, the inequality $\left[\begin{array}{cc}R_{i} & I \\ I & S_{i}\end{array}\right] \geq 0, i=1, \ldots, n$, was used, so there is no need to modify the numerical results.

The online version of the original article can be found under doi:10.1007/s11045-011-0148-1.

Z.-Y. Feng · L. Xu ( $ه)$

Department of Electronics and Information Systems, Akita Prefectural University, Yuri-Honjo, 015-0055 Akita, Japan e-mail: xuli@akita-pu.ac.jp

Z.-Y. Feng

e-mail: fengge81@gmail.com

Q. Wu

Department of Automatic Control, Beijing Institute of Technology, 100081 Beijing, China e-mail: qinghew@bit.edu.cn 